Note

\title{
Evaluation of the Biodegradability of Polyurethane and Its Derivatives by Using Lipase-Displaying Arming Yeast
}

\author{
SEIJI SHIBASAKI ${ }^{1}$, AI KAWABATA ${ }^{2}$, TAKANORI TANINO $^{3}$, AKIHIKO KONDO $^{3}$, \\ MITSUYOSHI UEDA ${ }^{4}$ AND MAMORU TANAKA ${ }^{2}$
}

\author{
${ }^{1}$ Department of Pharmacy, School of Pharmacy, Minatojima, Chuo-ku, Kobe 650-8530, Japan \\ ${ }^{2}$ Department of Applied Chemistry, Kobe City College of Technology, \\ Gakuenhigashi, Nishi-ku, Kobe 651-2194, Japan \\ ${ }^{3}$ Department of Chemical Science and Engineering, Graduate School of Engineering, \\ Kobe University, Rokkodaicho, Nada-ku, Kobe 657-8501, Japan \\ ${ }^{4}$ Department of Biomacromolecular Chemistry, Graduate School of Agriculture, Kyoto University, \\ Kitashirakawa-oiwakecho, Sakyo-ku, Kyoto 606-8502, Japan
}

Received 15 April, 2009/Accepted 5 June, 2009

\begin{abstract}
Candida antarctica lipase B (CALB) has been used to polymerize and degrade polyesters. We developed a convenient method for investigating the biodegradability of plastics that involves the use of CALB-displaying "arming yeast." Polyurethane containing dulcitol units was prepared and used as the model material. Additionally, standard polyurethane with no dulcitol units was prepared by reacting 2,4-toluene diisocyanate with ethylene glycol. These polymers were incubated with CALB-displaying yeast cells. The polyurethane containing dulcitol was degraded, while the standard polyurethane was relatively unaffected. Arming yeast displaying appropriate enzymes can be used to investigate the biodegradability of synthetic plastics. It was also revealed that arming yeasts were applicable to evaluate the degradation of the film state of polyurethane.
\end{abstract}

Key words : Arming yeast/Biodegradation/Dulcitol/Lipase / Polyurethane.

The demand for biodegradable plastics for use as medical materials or alternatives to fossil fuel-derived industrial plastics has been increasing. These plastics have been studied in detail for several decades (Xu et al., 2007), and in recent years, segmented polyester- and polyether-based polyurethanes have been used to produce elastomers, fibers, resins, paints, adhesives, etc. Furthermore, the enzymatic polymerization and degradation of these compounds have been investigated (Ihara et al., 1991; McCabe and Taylor, 2002; Soeda et al., 2004), and the activity of lipases (triacylglycerol acylhydrolases (EC 3.1.1.3)), in this regard, has been studied in detail. These enzymes are found in a wide variety of organ-

*Corresponding author. Tel : +81-78-304-3159, Fax : +8178-304-2859. E-mail: Seiji(a)huhs.ac.jp isms and are capable of hydrolyzing triglycerides at the lipid-water interface. In addition, these lipases have been used to degrade polyurethane plastics (Kobayashi et al., 2000), and Gautam et al. (2007) have shown successfully that Candida rugosa lipase could be applied in the evaluation of the degradation of polyurethane. However, these enzymes cannot be prepared easily at most laboratories.

Yeast has been well investigated not only with regard to its biochemistry and morphology (Shibasaki et al., 2008) but also for its use in applied microbiology for preparing biocatalysts. Since the 1990s, Saccharomyces cerevisiae has been used to display enzymes on the cell surface as a so-called "arming yeast" (Ueda et al., 2000; Shibasaki et al., 2003; Shibasaki et al., 2009). To produce an arming yeast, the gene encoding the enzyme to be displayed is 


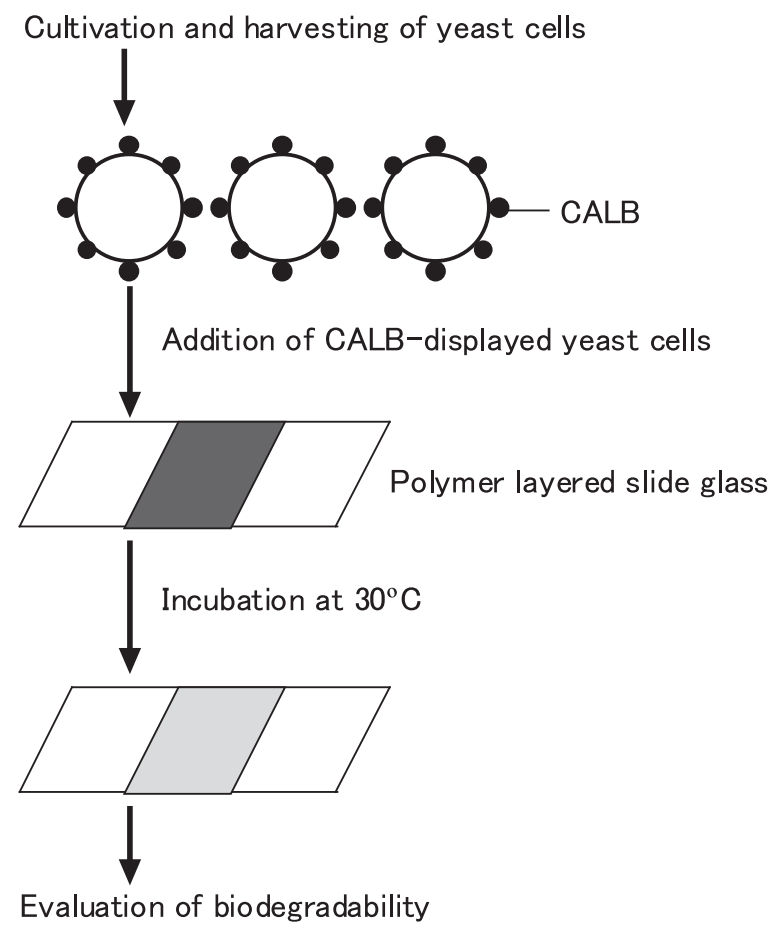

(Observation and measurement of a weight)

FIG. 1. The degradation of polyurethanes by lipasedisplaying arming yeast.

usually fused to the gene encoding the secretion signal sequence and the cell wall anchoring protein ( $\alpha$ agglutinin or Flo1), respectively. The enzyme is expressed under the control of a suitable promoter. By using the "arming technology," yeasts with novel functions can be created to display not only enzymes but also functional peptides or proteins (receptors, antibodies, and metal-binding peptides) for use as biotechnological tools.

Advantageous characteristics of such arming yeasts include self-proliferation and recyclability; moreover, they are considered to be whole-cell biocatalysts (Shiraga et al., 2002; Kato et al., 2005). Such whole-cell biocatalysts are easily created in the laboratory by using this technology and commonly used biotechnological equipment. We can also evaluate quantitatively the amount of enzyme on the cell surface by several methods (Shibasaki et al., 2001). To date, Candida antarctica lipase B (CALB) has been displayed on the surface of yeasts and used for studying the synthesis of polyester (Tanino et al., 2009). In this study, we propose a simple method to degrade polyurethane and demonstrate the suitability of the CALB-displaying arming yeast to evaluate the biodegradability of these plastics (Fig. 1). Here, we synthesized and evaluated a model material, a novel polyurethane with dulcitol as the hard segment.
First of all, $\beta$-Diisopropylidene dulcitol (DID) was synthesized by reacting dulcitol with acetone as follows: $50 \mathrm{~g}$ dulcitol (Wako, Osaka, Japan), 1,500 ml acetone (Wako), and $65 \mathrm{ml}$ conc. $\mathrm{HCl}$ were added into a 2 liter three-necked round-bottom flask equipped with a stirring bar, thermometer, and reflux condenser. The mixture was stirred at room temperature for $20 \mathrm{~h}$. The reaction mixture was neutralized by adding basic $\mathrm{PbCO}_{3}$, and the reaction residue was filtrated off. After evaporating the filtrate in vacuo, the precipitate was purified by fractional recrystallization to separate the $\alpha$ - and $\beta$-DID. Fractional recrystallization was carried out by adding petroleum ether to the acetone reaction mixture. The spectral data of $\beta$-DID were as follows: ${ }^{1} \mathrm{H}$ NMR $\left(D_{2} O\right)$ : $d=$ $1.5\left(\mathrm{~s}, 12 \mathrm{H},-\mathrm{CH}_{3}\right), 4.0\left(\mathrm{~m}, 8 \mathrm{H},-\mathrm{CH}_{2^{-}},-\mathrm{CH}-\right)$; fourier transform infrared (FT-IR) $(\mathrm{KBr}): 1,380 \mathrm{~cm}^{-1}\left(-\mathrm{CH}_{3}\right)$, $3,300 \mathrm{~cm}^{-1}(-\mathrm{OH})$. The spectral data and the melting point $\left(108^{\circ} \mathrm{C}\right)$ of $\beta$-DID corresponded to those obtained in a reference study (Tanaka and Nakaya, 1982), and the yield obtained was $9.05 \%$.

Polyurethane containing the dulcitol unit in the main chain (DPU) was synthesized by reacting $\beta$-DID with 2,4-toluene diisocyanate (2,4-TDI) (Wako) as follows: $1.74 \mathrm{~g} \beta$-DID was dissolved in $10 \mathrm{ml}$ absolute $\mathrm{N}, \mathrm{N}$-dimethylformamide (DMF) in a $50 \mathrm{~mL}$ threenecked round bottom flask equipped with a stirring bar, thermometer, and a dropping funnel and small amounts of the catalysts 1,4-diazabicyclo(2.2.2)octane and dibutyltin(IV) dilaurate were introduced. Half of the solution of 2,4-TDI in DMF was added to the mixture all at once, and the remaining half was carefully added to the mixture at $80^{\circ} \mathrm{C}$ over $2 \mathrm{~h}$. The reaction mixture was poured into water, and the polyurethane precipitate was obtained (Fig. 2a). The

(a)<smiles>[CH]OCC(O)C(O)C(O)C(O)COC(=O)Nc1ccc(C)c(N=CC(=O)O)c1</smiles>

(b)

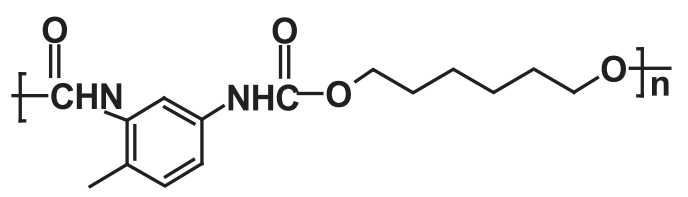

FIG. 2. The chemical structure of the polyester polyurethanes synthesized and evaluated in this study.
(a) Dulcitol-containing polyurethane

(b) Standard polyurethane 
precipitate was washed with acetone and dried under reduced pressure. Standard polyurethane (STPU) (Fig. 2b) was prepared by reacting 1,6-hexanediol and 2,4-TDI by using the method described above. The intrinsic viscosities of DPU and STPU were 0.13 $\mathrm{dl} / \mathrm{g}$ and $0.25 \mathrm{dl} / \mathrm{g}$, respectively.

To prepare a film for evaluating the biodegradation by CALB-displaying yeast (Fig. 1), STPU or DPU was dissolved in DMF to obtain a $10 \%$ (W/v) solution; each of these solutions was placed on a Micro Slide Glass S-1111 $(76 \times 26$ mm; Matsunami, Osaka, Japan), and the slides were kept at $60^{\circ} \mathrm{C}$ for $2 \mathrm{~h}$. The films thus obtained were soaked in diethyl ether to remove the solvent and dried under reduced pressure before they were subjected to biodegradation.
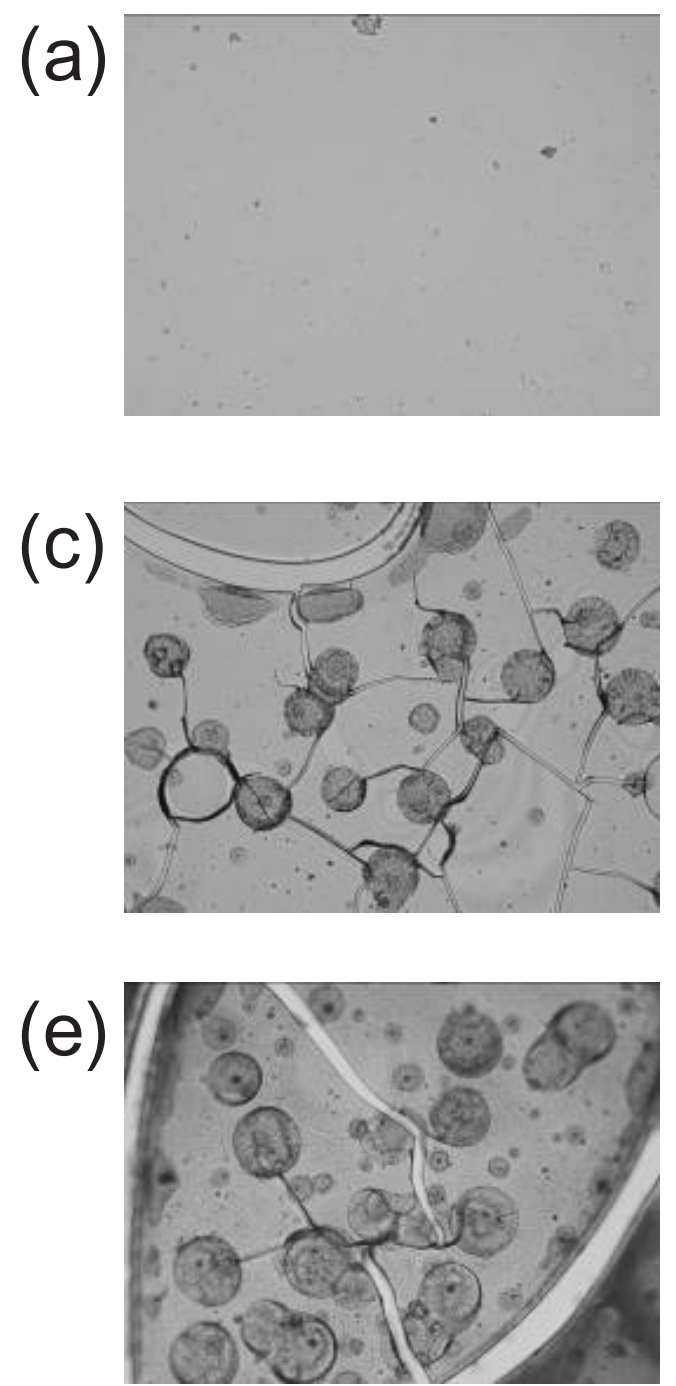

To examine the biodegradation of polyurethane materials, two kinds of yeast cells were prepared. $S$. cerevisiae YPH501 strain (MAT $\alpha / a$, ade2/ade2, his3/his3, leu2/leu2, trp1/trp1, ura3/ura3, lys2/lys2) was used as the control. S. cerevisiae 500ULHWA strain that displayed CALB on the cell surface was created by Tanino et al. (2009). The yeast was grown in either yeast extract/peptone/dextrose (YPD) medium (1\% ( $\mathrm{W} / \mathrm{v})$ yeast extract, $2 \%(\mathrm{w} / \mathrm{v})$ polypeptone, $2 \%(\mathrm{~W} / \mathrm{v})$ glucose) or in synthetic dextrose complete $(\mathrm{SDC})$ medium $(0.67 \%(\mathrm{w} / \mathrm{v})$ yeast nitrogen base without amino acids, $2 \%(\mathrm{w} / \mathrm{v})$ glucose, $1 \%(\mathrm{w} / \mathrm{v})$ casamino acids, supplemented with appropriate amino acids). SDC medium was used to induce the UPR-ICL promoter that controlled the dis-
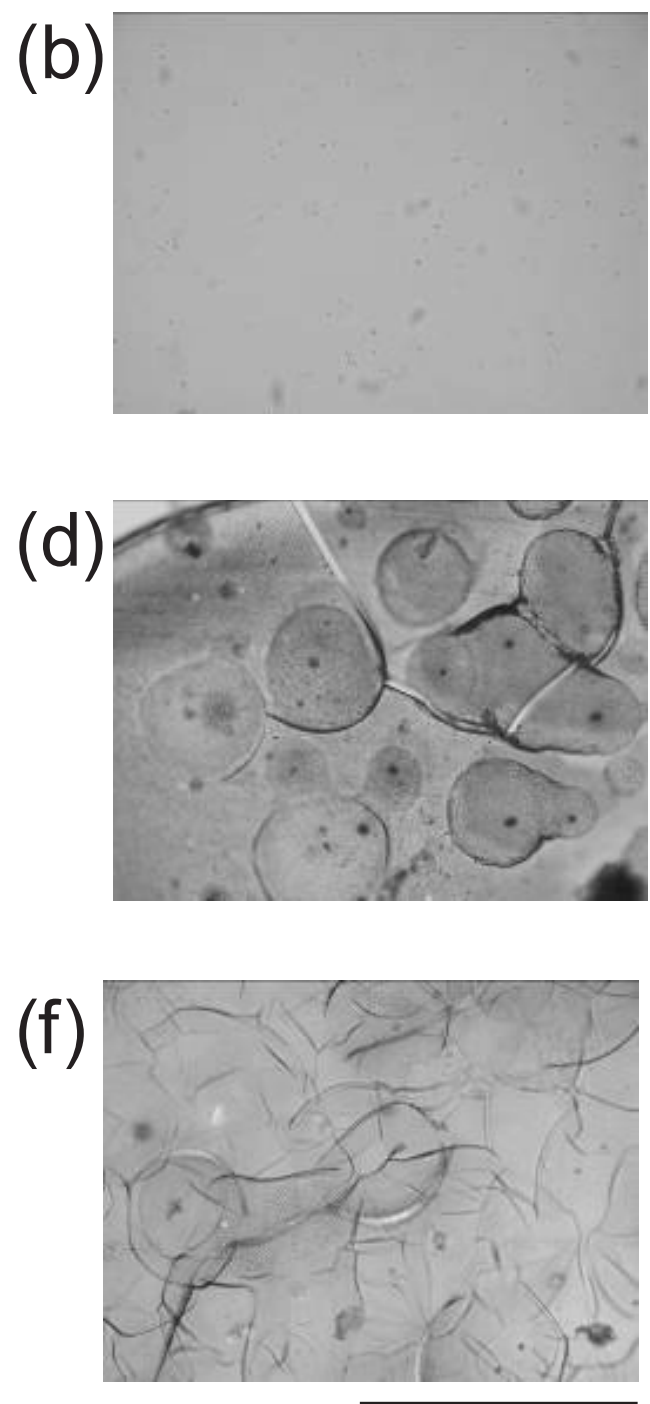

FIG. 3. Microscopic observation of the degraded polyurethane materials; STPU subjected to 500ULHWA cells (a and b); DPU subjected to YPH501 cells ( $c$ and d) and to 500ULHWA cells (e and f). Observation at 1 week ( $a, c, e)$ and 2 weeks (b, d, f). Bar, $0.3 \mathrm{~mm}$. 
play of CALB on the surface. The control strain YPH501 and the CALB-displaying 500ULHWA cells grown in YPD medium did not exhibit lipase activity. However, 500ULHWA cells grown in SDC medium exhibited lipase activity, and the activity peaked at approximately $6 \mathrm{~d}$. This finding suggested that CALB was successfully displayed under the control of the UPR-ICL promoter, and the cell surface was saturated with CALB. The activity was confirmed by using the method described by Tanino et al. (2009) (data not shown).

After precultivation of the YPH501 or 500ULHWA cells for $24 \mathrm{~h}$ in YPD medium, the cells were inoculated into SDC medium and further cultivated for $6 \mathrm{~d}$. The cells were harvested from the SDC medium and resuspended in fresh $20 \mathrm{ml}$ of SDC medium. The cell density was adjusted to $8.2 \mathrm{mg}$ cell $\mathrm{dry} / \mathrm{ml}$ and the medium was poured into a Petri dish. The polyurethane film-layered slide glass was placed on the Petri dish and incubated at $30^{\circ} \mathrm{C}$. After gentle mixing for 2 weeks, the slide glass was first washed with distilled, sterilized water and then analyzed by 2 methods: microscopic observation and measurement of weight reduction.

Initially, the incubated polyurethane film was investigated by light-field microscopy. Microscopic observation was carried out by using a BX-51 microscope (Olympus, Tokyo, Japan) and micrographs were obtained with a digital camera (Camedia; Olympus). The microscopic observation of the control polyurethane STPU treated with 500ULHWA cells revealed no destructive changes, but the film turned slightly yellow in the second week due to the medium (Fig. $3 \mathrm{~b}$ ). On the other hand, apparent degradation of DPU subjected to both the control strain YPH501 (Fig. 3c and $3 \mathrm{~d}$ ) and CALB-displaying 500ULHWA cells (Fig. $3 e$ and $3 f$ ) was observed; many cracks were found on the surface of this polyurethane material. These results suggest that DPU was more susceptible to degradation as compared to STPU because of the introduction of the hydrophilic dulcitol unit.

Next, we measured the weight of the polyurethane film-layered slide glass both before and after biodegradation by using a semi-micro balance (AUW220D; Shimadzu, Kyoto, Japan). After biodegradation, the exfoliated polyurethane film was recovered and washed to remove cells and medium. Although microscopic examination did not reveal remarkable changes in the STPU film treated with 500ULHWA, a slight loss in weight was detected (Fig. 4). On the other hand, the weights of both the DPU samples treated with the control strain YPH501 and 500ULHWA cells were considerably decreased. Approximately $5 \%$ higher degradation was confirmed for DPU with 500ULHWA cells than with of YPH501 cells. Although the degradation of DPU can be attributed to a certain extent to the activity of the cell surface CALB, it is thought to be driven by another fact or-i.e., the cleavage of the peptide bond in the urethane structure (Fig. 1) by secreted proteases of the yeast. To clarify this, further microscopic observation and weight measurement should be continued.

In summary, CALB-displaying arming yeast, as a whole-cell biocatalyst which can be prepared conveniently, was used to examine the biodegradation of synthetic polymers. This is the first report showing that immobilized enzymes on the yeast cell surface can successfully degrade polyurethane as a film-state substrate. A polyurethane film containing dulcitol was successfully degraded by an arming yeast in aqueous SDC medium. Our studies also showed that polyurethane containing dulcitol in the main chain can be degraded by the action of enzymes. The technique used in this study is a novel and convenient tool for investigating the biodegradability of polyurethanes and other polyesters. Moreover, microscopy is a simple technique, and weight measurement is preferred because it is a precise and convenient method for evaluating the biodegradation of polyurethane films. To enhance the degradation of plastics by an arming yeast, the enzymatic reaction involved in such processes should be optimized further. Other than displaying hydrolytic enzymes like CALB, the display of enzymes such as oxidoreductase might aid in the biodegradation of plastics that are not easily degraded by natural microorganisms. Although we introduced dulcitol to possibly enhance degradation, the influence of this compound has not yet been con-

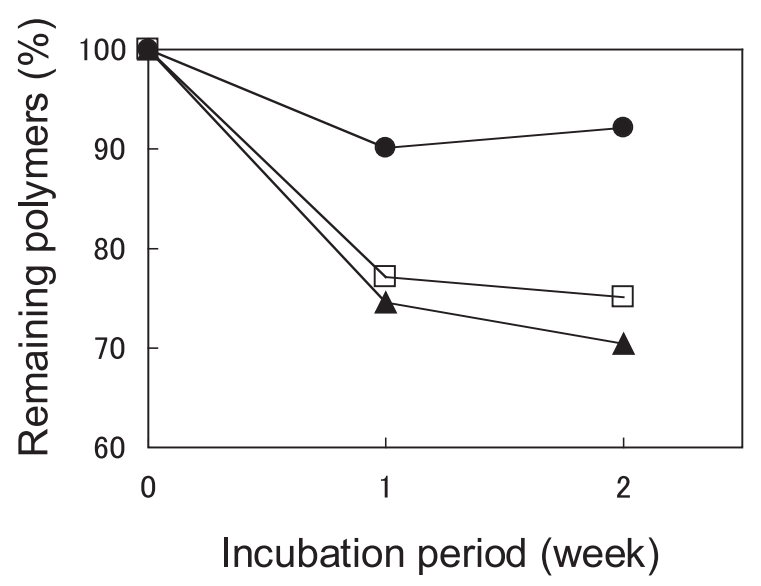

FIG. 4. Weight measurement of the degraded polyurethane materials. STPU subjected to YPH501 cells (O); DPU subjected to YPH501 cells ( $\square$ ); and DPU subjected to 500ULHWA cells ( $\mathbf{A})$. Each point represents the average of 3 independent experiments. 
firmed. In addition to confirming the role of dulcitol in the degradation, studies on the recovery and reuse of the CALB-displaying arming yeast are currently in progress; the results of which will be reported upon completion.

\section{ACKNOWLEDGMENTS}

This work was partially supported by grants from Chemicals Evaluation and Research Institute, Japan.

\section{REFERENCES}

Gautam, R., Bassi, AS., and Yanful, E.K. (2007) Candida rugosa lipase-catalyzed polyurethane degradation in aqueous medium. Biotechnol. Lett., 29, 1081-1086.

Ihara, F., Kageyama, Y., Hirata, M., Nihira, T., and Yamada, Y. (1991) Purification, characterization, and molecular cloning of lactonizing lipase from Pseudomonas species. J. Biol. Chem., 266, 18135-18140.

Kato, M., Maeda, H., Kawakami, M., Shiraga, S., and Ueda, M. (2005) Construction of a selective cleavage system for a protein displayed on the cell surface of yeast. Appl. Microbiol. Biotechnol., 69, 423-427.

Kobayashi, S., Uyama, H., and Takamoto, T. (2000) Lipase-catalyzed degradation of polyesters in organic solvents. A new methodology of polymer recycling using enzyme as catalyst. Biomacromolecules, 1, 3-5.

Kondo, A., and Ueda, M. (2004) Yeast cell-surface display-applications of molecular display. Appl. Microbiol. Biotechnol., 64, 28-40.

McCabe, R.W., and Taylor, A. (2002) Synthesis of novel polyurethane polyesters using the enzyme Candida antarctica lipase B. Chem. Commun. (Camb), 7, 934935.

Shibasaki, S., Maeda, H., and Ueda, M. (2009) Molecular display technology using yeast - arming technology. Anal. Sci., 25, 41-49.

Shibasaki, S., Okada, J., Nakayama, Y., Yoshida, T., and Ueda, M. (2008) Isolation of bacteria which produce yeast cell wall-lytic enzymes and their characterization.
Biocontrol. Sci., 13, 91-96.

Shibasaki, S., Tanaka, A., and Ueda, M. (2003) Development of combinatorial bioengineering using yeast cell surface display-order-made design of cell and protein for bio-monitoring. Biosens. Bioelectron., 19, 123130.

Shibasaki, S., Ueda, M., lizuka, T., Hirayama, M., Ikeda, Y., Kamasawa, N., Osumi, M., and Tanaka, A. (2001) Quantitative evaluation of the enhanced green fluorescent protein displayed on the cell surface of Saccharomyces cerevisiae by fluorometric and confocal laser scanning microscopic analyses. Appl. Microbiol. Biotechnol., 55, 471-475.

Shiraga, S., Ueda, M., Takahashi, S., and Tanaka, A. (2002) Construction of the combinatorial library of Rhizopus oryzae lipase mutated in the lid domain by displaying on yeast cell surface. J. Mol. Catal. B: Enz., 17, 167-173.

Soeda, Y., Toshima, K., and Matsumura, S. (2004) Enzymatic synthesis and chemical recycling of poly (carbonate-urethane). Macromol. Biosci. 4, 721-728.

Tanaka, M., and Nakaya, T. (1982) The interactions polyurethanes containing dulcitol with some metal ions (in Japanse). Kobunshi Ronbunshu, 39, 109-114.

Tanino, T., Aoki, T., Chung, W.Y., Watanabe, Y., Ogino, C., Fukuda, H., and Kondo, A. (2009) Improvement of a Candida antarctica lipase B-displaying yeast whole-cell biocatalyst and its application to the polyester synthesis reaction. Appl. Microbiol. Biotechnol., 82, 59-66.

Ueda, M., and Tanaka, A. (2000) Genetic immobilization of proteins on the yeast cell surface. Biotechnol. Adv., 18, 121-140.

Umemura, K,, Atomi, H., Kanai, T., Takeshita, S., Kanayama, N., Ueda, M., and Tanaka, A. (1997) Derepression of gene expression mediated by the 5' upstream region of the isocitrate lyase gene of Candida tropicalis is controlled by two distinct regulatory pathways in Saccharomyces cerevisiae. Eur. J. Biochem., 243, 748-752.

Xu, S., Yamaguchi, T., Osawa, S., and Suye, S. (2007) Biodegradation of poly (epsilon-caprolactone) film in the presence of Lysinibacillus sp. 70038 and characterization of the degraded film. Biocontrol. Sci., 12, 119-122. 